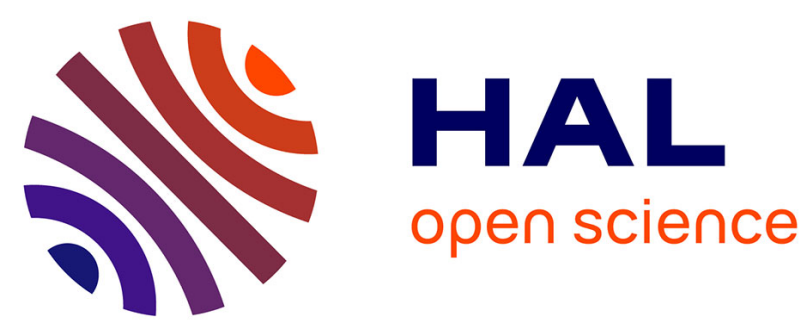

\title{
Some preliminary results on the action of rhamnogalacturonase on rhamnogalacturonan oligosaccharides from beet pulp
}

C.M.G.C. Renard, J.F. Thibault, M. Mutter, H.A. Schols, A.G.J. Voragen

\section{To cite this version:}

C.M.G.C. Renard, J.F. Thibault, M. Mutter, H.A. Schols, A.G.J. Voragen. Some preliminary results on the action of rhamnogalacturonase on rhamnogalacturonan oligosaccharides from beet pulp. International Journal of Biological Macromolecules, 1995, 17 (6), pp.333-336. hal-02712104

\section{HAL Id: hal-02712104 \\ https://hal.inrae.fr/hal-02712104}

Submitted on 1 Jun 2020

HAL is a multi-disciplinary open access archive for the deposit and dissemination of scientific research documents, whether they are published or not. The documents may come from teaching and research institutions in France or abroad, or from public or private research centers.
L'archive ouverte pluridisciplinaire HAL, est destinée au dépôt et à la diffusion de documents scientifiques de niveau recherche, publiés ou non, émanant des établissements d'enseignement et de recherche français ou étrangers, des laboratoires publics ou privés.

\section{(c)(1)}

Distributed under a Creative Commons Attribution| 4.0 International License 


\title{
Some preliminary results on the action of rhamnogalacturonase on rhamnogalacturonan oligosaccharides from beet pulp
}

\author{
C. M. G. C. Renard*, J.-F. Thibault \\ Laboratoire de Biochimie et Technologie des Glucides, Centre de Recherche \\ Agro-alimentaire, Institut National de la Recherche Agronomique, BP 1627, 44326 Nantes \\ Cedex 03, France
}

M. Mutter, H. A. Schols and A. G. J. Voragen

Department of Food Science, Wageningen Agricultural University, PO Box 8129, 6700 EV Wageningen, The Netherlands

Received 30 September 1994; revised 16 January 1995

\begin{abstract}
Sugar-beet pulp was saponified and then hydrolysed with $0.1 \mathrm{M} \mathrm{HCl}$ at $80^{\circ} \mathrm{C}$ for $72 \mathrm{~h}$, and a rhamnogalacturonan fraction was isolated by ion-exchange chromatography on AG 1 X8 resin. Four individual oligomers, and a mixture of oligomers with higher degrees of polymerization, were obtained by chromatography on BioGel P-4. They all presented the $\alpha$-D-GalAp- $\left(1[\rightarrow 2)-\alpha\right.$-L-Rhap- $\left.(1 \rightarrow 4)-\alpha-\mathrm{D}-\mathrm{GaIA} p-(1]_{n} \rightarrow 2\right)$-L-Rhap structure (with $n \geqslant 2$ ) The five fractions were submitted to hydrolysis with rhamnogalacturonase. The enzyme was active on oligomers with degrees of polymerization $\geqslant 10$, and gave as main products $\alpha$-L-Rhap- $(1 \rightarrow 4)-\alpha$-D-GalAp- $(1 \rightarrow 2)-\alpha$-L-Rhap $(1 \rightarrow 4)-D$-GalAp and $\alpha$-D-GalAp- $(1 \rightarrow 2)-\alpha$ L-Rhap- $(1 \rightarrow 4)-\alpha-D$-GalAp- $(1 \rightarrow 2)-\alpha-$ L-Rhap- $(1 \rightarrow 4)$-D-GalAp
\end{abstract}

Keywords: rhamnogalacturonan; rhamnogalacturonase; sugar beet

Pectins are plant cell-wall polysaccharides which comprise two distinct structural features: 'smooth regions', composed of $(1 \rightarrow 4)$-linked $\alpha$-D-galacturonic acid residues, with degrees of polymerization $>100^{1}$, and 'hairy regions', where a rhamnogalacturonan backbone, composed to a large extent of alternating 2-linked $\alpha-L-$ rhamnose and 4-linked $\alpha$-D-galacturonic acid residues, carries side chains (on the $\mathrm{O} 4$ position of rhamnose residues) composed essentially of galactose and arabinose residues $^{2,3}$. Rhamnogalacturonan regions typically contain about $5 \%$ of the galacturonic acid residues and may be isolated after degradation of pectins ${ }^{4}$ or cell walls ${ }^{2}$ by pectolytic enzymes.

Rhamnogalacturonase is an enzyme which cleaves the main chain of pectins in the rhamnogalacturonan areas. It has been isolated from a commercial preparation of Aspergillus aculeatus ${ }^{5}$ and culture broth from Trametes sanguinea $a^{6}$, and its end products from isolated 'modified hairy regions' are oligomers with a basic structure of $\alpha$-L-Rhap-(1 $\rightarrow 4)-\alpha-\mathrm{D}-\mathrm{GalA} p-(1 \rightarrow 2)-\alpha-\mathrm{L}-\mathrm{Rhap}-(1 \rightarrow 4)$ D-GalA $p^{3}$.

\footnotetext{
*To whom correspondence should be addressed
}

Although rhamnogalacturonase is known to hydrolyse linkages within the rhamnogalacturonan backbone, and is even able to extract pectins from apple cell walls ${ }^{7}$, the exact mechanism is not completely understood. During acid hydrolysis of pectins ${ }^{1}$, we identified a fraction representative of the rhamnogalacturonan backbone of pectins. We have now isolated and characterized a series of rhamnogalacturonan oligomers from an acid hydrolysate of sugar-beet pulp. Subsequently, we incubated these oligosaccharides with rhamnogalacturonase and studied the products liberated.

\section{Experimental}

Materials

Sugar-beet pulp from Sofalia (Ennezat, France) was de-esterified as described previously ${ }^{8}$; rhamnogalacturonase was isolated from a commercial preparation of Aspergillus aculeatus as described by Schols et al. ${ }^{5}$.

\section{Acid hydrolysis}

Eight grams of de-esterified beet pulp were hydrolysed in $0.1 \mathrm{M} \mathrm{HCl}$ at $80^{\circ} \mathrm{C}$ for $72 \mathrm{~h}^{1}$. After hydrolysis, the slurry 
was filtered on a G4 sintered glass filter. The filtrate was neutralized to $\mathrm{pH} 5.9$ with $\mathrm{NaOH}$ and filtered again before chromatography. The residue was dried by solvent exchange after washing.

\section{Fractionation of the acid hydrolysate}

Ion-exchange chromatography was performed on an AG 1 X8 column $(1.6 \times 54 \mathrm{~cm})$ (BioRad, St Louis, MO, USA) eluted with ammonium acetate buffer, $\mathrm{pH} 6$, at a flow rate of $1.33 \mathrm{ml} \mathrm{min}{ }^{-1}$. The column was first washed with $150 \mathrm{ml}$ of $0.05 \mathrm{M}$ buffer, followed by a gradient up to $1.2 \mathrm{M}$ in $600 \mathrm{ml}$ and then to $2 \mathrm{M}$ in $200 \mathrm{ml}$. Gel-permeation chromatography on a BioGel P-4 column $(2.5 \times 90 \mathrm{~cm})$ (BioRad), eluted with $0.1 \mathrm{M}$ acetate buffer, $\mathrm{pH} 3.6$, was carried out according to the method described by Thibault ${ }^{9}$. In all cases, the collected tubes were assayed for uronic acid and neutral sugars. Fractions were desalted by filtration on a Sephadex G-10 column $(5 \times 60 \mathrm{~cm})$ (Pharmacia, Uppsala, Sweden) eluted with water, and freeze-dried.

\section{Enzyme assays}

The oligomers $\left(0: 5 \mathrm{mg} \mathrm{ml}^{-1}\right.$ in $50 \mathrm{~mm}$ acetate buffer, $\mathrm{pH} \mathrm{5)} \mathrm{were} \mathrm{incubated} \mathrm{with} 45 \mu \mathrm{g} \mathrm{ml}^{-1}$ of rhamnogalacturonase at room temperature. The enzyme was inactivated by treatment for $5 \mathrm{~min}$ at $100^{\circ} \mathrm{C}$. The incubation was followed by high-performance anionexchange chromatography (HPAEC) on a CarboPac PA100 column $(4 \times 250 \mathrm{~mm})$ with guard column. The chromatographic system was a Dionex Bio-LC system (Sunnyvale, CA, USA), including a quaternary gradient pump, eluent de-gas (helium) module, and a pulsed electrochemical detector in the pulsed amperometric detection (PAD) mode. A Spectra Physics SP8800 autosampler (San José, CA, USA) and a Spectra Physics Winner data collection system were used. The column was eluted at a flow rate of $1 \mathrm{ml} \mathrm{min}^{-1}$ by a gradient of NaOAc in 0.1 M NaOH: from $150 \mathrm{~mm} \mathrm{NaOAc}$ to $600 \mathrm{~mm}$ $\mathrm{NaOAc}$ in $50 \mathrm{~min}$ then to $1 \mathrm{M} \mathrm{NaOAc}$ in $10 \mathrm{~min}$, and re-equilibration with $150 \mathrm{~mm} \mathrm{NaOAc}$ for $15 \mathrm{~min}$.

\section{Analytical methods}

Galacturonic acid and total neutral sugar concentrations were measured by automated meta-hydroxy- dipheny $1^{10}$ and orcinol assays ${ }^{11}$, respectively. Corrections were made for interference of uronic acids in the neutral sugars assay. Individual neutral sugars were analysed as their alditol acetate derivatives by gas chromatography ${ }^{12}$ after $2 \mathrm{~h}$ hydrolysis by $2 \mathrm{M}$ trifluoroacetic acid (TFA) at $120^{\circ} \mathrm{C}$ or $3 \mathrm{~h}$ hydrolysis by $1 \mathrm{M} \mathrm{H}_{2} \mathrm{SO}_{4}$ at $100^{\circ} \mathrm{C}^{13}$, preceded by $1 \mathrm{~h}$ pre-hydrolysis in $72 \% \mathrm{H}_{2} \mathrm{SO}_{4}$ for de-esterified beet pulp and the residue from acid hydrolysis. Degrees of methylation (DM) and acetylation (DA) were calculated as molar ratios from the contents of methanol and acetic acid, respectively, determined according to the method described by Voragen et al. ${ }^{14}$, and of galacturonic acid.

\section{Results}

\section{Isolation of rhamnogalacturonan oligosaccharides}

De-esterified sugar-beet pulp, as reported previously ${ }^{8}$, was found to be rich in arabinose, glucose and galacturonic acid $(234,237$ and $183 \mathrm{mg}$ per $\mathrm{g}$ dry weight, respectively), with minor amounts of galactose and rhamnose ( 57 and $19 \mathrm{mg}$ per g). Despite the deesterification treatment, residual methanol $(\mathrm{DM}=7)$ and acetic acid $(\mathrm{DA}=5)$ could be detected. The residue from acid hydrolysis was enriched in glucose (533 mg per g), galacturonic acid (288 $\mathrm{mg}$ per g), xylose ( $22 \mathrm{mg}$ per g) and mannose $(26 \mathrm{mg}$ per $\mathrm{g})$, and almost devoid of rhamnose ( $3 \mathrm{mg}$ per $\mathrm{g}$ ), arabinose $(1 \mathrm{mg}$ per $\mathrm{g}$ ) and galactose $(0 \mathrm{mg}$ per g). Enrichment in galacturonic acid of the residue is due to the insolubility of the homogalacturonic regions under acidic conditions ${ }^{1}$. The hydrolysate (Table l) was very rich in arabinose and rich in galactose and galacturonic acid. Sugar analysis without hydrolysis before derivatization showed that $82 \%$ of the arabinose and $50 \%$ of the galactose, but only $12 \%$ of the rhamnose, were present as monomers.

Ion-exchange chromatography of the acid hydrolysate (Figure $1 a$ and Table 1) resulted in one major, non-retained fraction (fraction 1). This fraction contained the majority of all the neutral sugars, except rhamnose, which was mostly retained on the column. In fraction 1 , rhamnose was mostly $(85 \%)$ present in monomeric form. Six acidic peaks were obtained, of which five were analysed for their neutral sugar content, with the last

Table 1 Compositions (mol\%) of the beet-pulp hydrolysate and its fractions. See Figure 1 for identification of the fractions

\begin{tabular}{|c|c|c|c|c|c|c|c|c|}
\hline & Rha & Fuc & Ara & Xyl & Man & Gal & Gle & GalA \\
\hline Acid hydrolysate & 5.6 & 0.4 & 65.4 & 1.7 & 0.2 & 12.7 & 0.6 & 13.4 \\
\hline \multicolumn{6}{|c|}{ Ion-exchange fractions } & & & 1.7 \\
\hline $\begin{array}{l}1 \\
2\end{array}$ & $\begin{array}{l}1.0 \\
7.2\end{array}$ & $\begin{array}{l}0.5 \\
0\end{array}$ & $\begin{array}{r}79.0 \\
0.8\end{array}$ & $\begin{array}{l}2.0 \\
6.1\end{array}$ & $\begin{array}{l}0.2 \\
0.5\end{array}$ & $\begin{array}{l}14.8 \\
33.3\end{array}$ & $\begin{array}{l}0.9 \\
1.1\end{array}$ & $\begin{aligned} 1.1 \\
51.1\end{aligned}$ \\
\hline 3 & 33.2 & 2.8 & 0 & 2.3 & 1.1 & 10.7 & 1.3 & 48.6 \\
\hline 4 & 49.0 & 0 & 0.5 & 0.3 & 1.3 & 0.9 & 0.5 & 47.6 \\
\hline 5 & 18.4 & 0 & 0.3 & 0.3 & 0 & 0.8 & 1.2 & 79.0 \\
\hline 6 & 11.2 & 0 & 0.2 & 0.3 & 0 & 0.4 & 1.2 & 86.7 \\
\hline \multicolumn{9}{|c|}{ Gel-permeation fractions } \\
\hline $4 \mathrm{~A}$ & 47.2 & 0 & 1.0 & 0.4 & 1.5 & 1.3 & 0.7 & 48.0 \\
\hline 4B & 53.5 & 0 & 0 & 0 & 1.1 & 0.6 & 1.6 & 43.3 \\
\hline $4 \mathrm{C}$ & 52.0 & 0 & 0.6 & 0 & 0.9 & 0.7 & 0 & 45.9 \\
\hline 4D & 48.5 & $\mathbf{0}$ & 0 & 0 & 1.3 & 0.6 & 0 & 49.7 \\
\hline $4 \mathrm{E}$ & 61.0 & 0 & 0.4 & 1.0 & 1.9 & 1.1 & 0.7 & 33.8 \\
\hline
\end{tabular}

All values were obtained after TFA hydrolysis, except for the acid hydrolysate and fraction 1, for which the molar percentages were calculated from All values were obtained after TFA hydrolysis, except for the acid hydrolysate and fraction 1, for which the mone
the concentrations found after TFA hydrolysis for rhamnose, mannose and glucose, and after $\mathrm{H}_{2} \mathrm{SO}_{4}$ hydrolysis for the other neutral sugars ${ }^{13}$ 

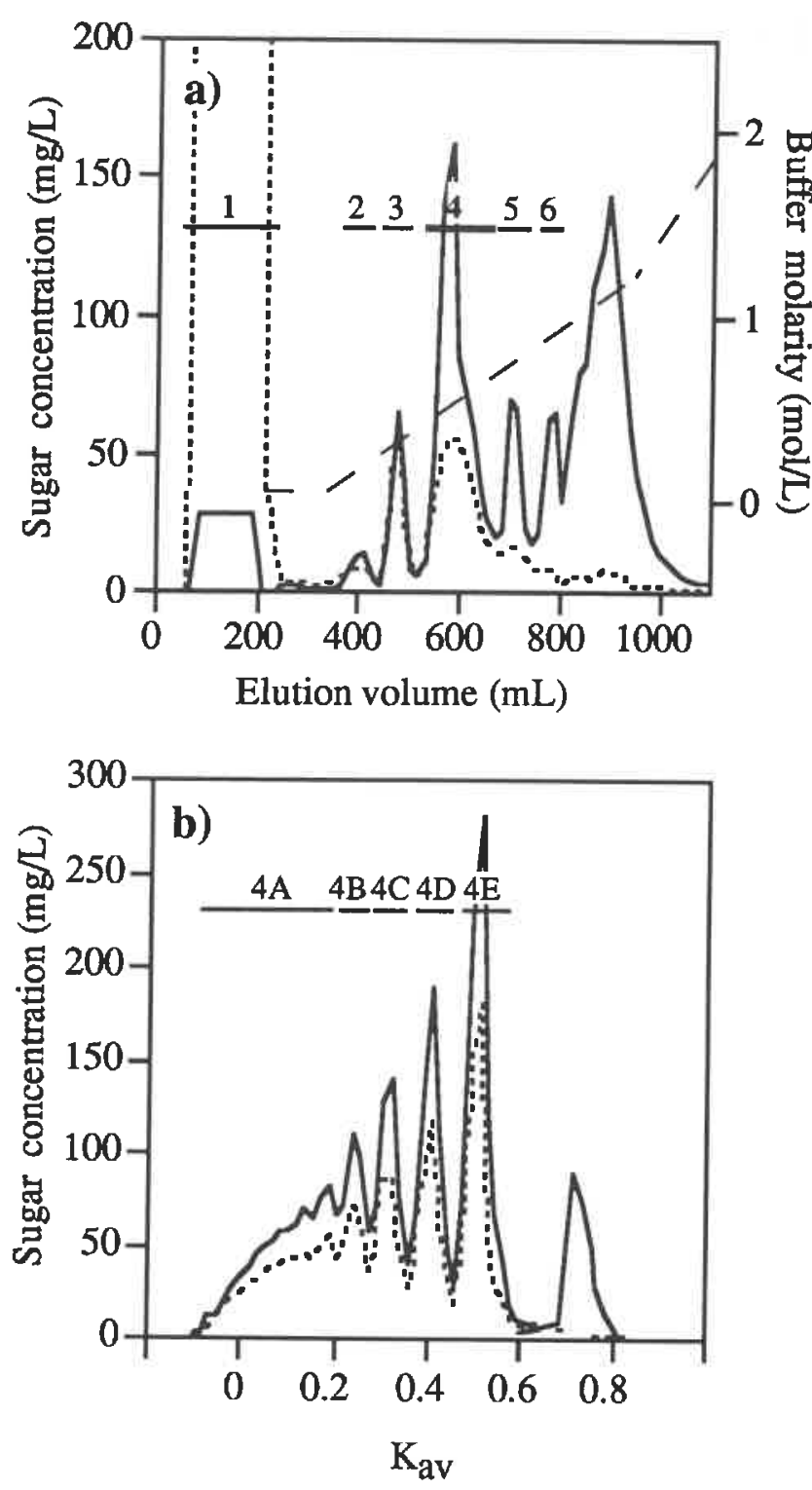

Figure 1 Fractionation of the acid hydrolysate from beet pulp: (a) on an $A G 1 X 8$ column (ion exchange); (b) on a BioGel P-4 column (ge permation): ( $\longrightarrow$ galacturonic acid; (-.....) neutral sugars; (- ammonium acetate buffer, $\mathrm{pH} 6$

peak being almost devoid of neutral sugars. Rhamnose was the main neutral sugar of the retained fractions, except fraction 2 (galactose). Fractions 4 to 6 contained nearly only rhamnose and galacturonic acid, with an increasing proportion of galacturonic acid as the elution proceeded. Fraction 4, which was the main rhamnogalacturonic acid fraction and had a rhamnose: galacturonic acid ratio of $\sim 1$, was further fractionated on BioGel P-4 (Figure 1 b). Its gel-permeation pattern showed one purely acidic fraction, eluting at a $K_{\text {ay }}$ value of 0.75 , and a series of rhamnogalacturonan oligosaccharides (Table 1). Fractions 4B to 4D were composed almost exclusively of rhamnose and galacturonic acid in $\sim$ 1:1 molar ratio and were shown by HPAEC (Figure 2) to contain one major product. Fraction $4 \mathrm{~A}$ contained a series of oligomers, as expected from the gel-permeation pattern. Fraction 4E, which had a higher rhamnose content, was composed of at least three oligomers. Except for fraction 4E, the BioGel P-4 and HPAEC patterns
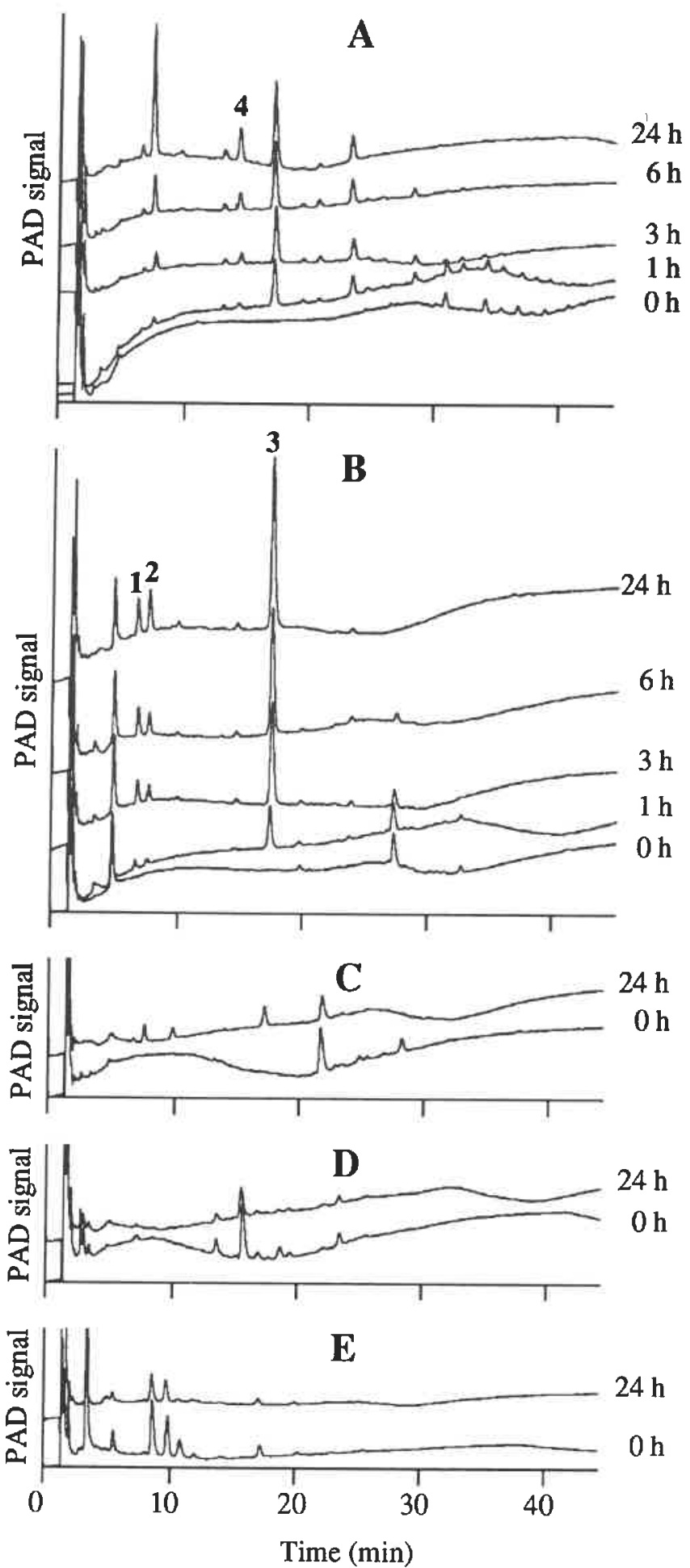

Figure 2 HPAEC analysis of the rhamnogalacturonan oligosaccharides isolated from a sugar-beet pulp acid hydrolysate by chromatography on AG 1 X8 columns (ion exchange) and on BioGel P-4 columns (gel permation), and their reaction products with rhamnogalacturonase. A, B, C, D, E: patterns for fractions $4 A, 4 B, 4 C, 4 D$ and $4 E$, respectively, from Figure $1 b$. $0 \mathrm{~h}$ : fractions prior to incubation with rhamnogalacturonase. $1 \mathrm{~h}, 3 \mathrm{~h}, 6 \mathrm{~h}, 24 \mathrm{~h}$ : fractions after $1 \mathrm{~h}, 3 \mathrm{~h}, 6 \mathrm{~h}, 24 \mathrm{~h}$ incubation with rhamnogalacturonase. PAD: pulsed amperometric detection

point to the presence of a series of homologous rhamnogalacturonan oligosaccharides. These oligomers did not co-elute on the Carbo-Pak PA100 column with rhamnogalacturonan oligosaccharides generated 
by rhamnogalacturonase treatment of 'modified hairy regions $^{15}$. Together with the known sensitivity to acid hydrolysis of glycosidic bonds ${ }^{16}$, this led us to propose the following structure: $\alpha-\mathrm{D}-\mathrm{GalA} p-(1[\rightarrow 2)-\alpha-\mathrm{L}-\mathrm{Rh}$ h $p$ $\left.(1 \rightarrow 4)-\alpha-\mathrm{D}-\mathrm{GalAp}-(1]_{n} \rightarrow 2\right)$-L-Rhap. Calibration of the column with oligogalacturonides indicated degrees of polymerization of $6(4 \mathrm{E}), 8(4 \mathrm{D}), 10(4 \mathrm{C})$ and 12 (4B) for the rhamnogalacturonan oligomers (i.e. $3,4,5$ and 6 repeats, respectively, of a galacturonic acid-rhamnose repeating unit).

\section{Action of rhamnogalacturonase on the rhamnogalacturonan oligosaccharides}

The effect of rhamnogalacturonase on the rhamnogalacturonan oligosaccharides is shown in Figure 2. It was not active on oligomers 4E and 4D. Even after $24 \mathrm{~h}$, fraction $4 \mathrm{C}$ showed only limited changes, which might actually be due to degradation of some contaminating material from fraction 4B. However, the rhamnogalacturonase had a marked effect on fractions $4 \mathrm{~B}$ and $4 \mathrm{~A}$. The oligosaccharide from fraction $4 \mathrm{~B}$ was cleaved to give three reaction products, two of which were identified by comparison with standards: peak 2 eluted at the same time as $\alpha$-L-Rhap- $(1 \rightarrow 4)-\alpha-\mathrm{D}-\mathrm{GalA} p-(1 \rightarrow 2)-\alpha-\mathrm{L}-\mathrm{Rh}$ - $p$ $(1 \rightarrow 4)-\mathrm{D}-\mathrm{GalA} p^{15}$, and peak 3 eluted at the same time as $\alpha-\mathrm{D}-\mathrm{GalA} p-(1 \rightarrow 2)-\alpha-\mathrm{L}-\mathrm{Rha} p-(1 \rightarrow 4)-\alpha-\mathrm{D}-\mathrm{GalA} p-(1 \rightarrow 2)-$ $\alpha$-L-Rhap- $(1 \rightarrow 4)-\mathrm{D}-\mathrm{GalA} p^{17}$. No standards were available for peak 1 , but since an $\alpha$-rhamnohydrolase ${ }^{17}$ could cleave it, releasing rhamnose, it probably represents the oligomer $\alpha$-L-Rhap- $(1 \rightarrow 4)-\alpha-\mathrm{D}-\mathrm{GalA} p-(1 \rightarrow 2)$-L-Rhap. The rhamnohydrolase ${ }^{17}$ also released rhamnose from peak 2 , but was inactive with regard to peak 3 . Reassembly of these oligosaccharides in a strictly alternating pattern of rhamnose and galacturonic acid gives the following order: 2-3-1, i.e. once again rhamnose was at the reducing end. Treatment of the mixture of oligomers in fraction $4 \mathrm{~A}$ resulted in a limited number of reaction products, including those identified above and the higher homologue $\alpha$-L-Rhap- $\left(1-[\rightarrow 4)-\alpha-\mathrm{D}-\mathrm{GalA} p-(1 \rightarrow 2)-\alpha-\mathrm{L}-\mathrm{Rhap}-(1-]_{2} \rightarrow 4\right)-\mathrm{D}-$ GalAp (peak 4$)^{15}$.

\section{Conclusion}

By controlled acid hydrolysis of de-esterified beet pulp, we obtained a series of rhamnogalacturonan oligosaccharides devoid of side chains. Rhamnogalacturonase was able to cleave the oligomers with a degree of polymerization $\geqslant 10$. Identification of the reaction products confirmed that the oligomers presented the strictly alternating structure which has already been described for the rhamnogalacturonan regions of the backbone of pectins ${ }^{2,3}$. Identification of the reaction products confirmed that these oligosaccharides presented inverted extremities compared to the oligomers produced by action of the rhamnogalacturonase on isolated 'modified hairy regions" 15 , i.e. they had a terminal galacturonic acid residue and a rhamnose residue at the reducing end. This was to be expected, as a neutral sugar to uronic acid bond is more sensitive to acid hydrolysis than a uronic acid to neutral sugar bond ${ }^{16}$. The time course studies, which showed proportional evolution of the peaks of all three reaction products for oligomer $4 \mathrm{~B}$ (keeping in mind the widely varying response factors obtained during PAD detection), indicated that the enzyme cleaved the rhamnogalacturonan backbone simultaneously at two points. These results require confirmation by more detailed structural determinations and further kinetic studies.

\section{Acknowledgements}

The authors are grateful to Miss J. Vigouroux for excellent technical assistance.

\section{References}

1 Thibault, J.-F., Renard, C.M.G.C., Axelos, M.A.V., Roger, P. and Crépeau, M.-J. Carbohydr. Res. 1993, 238, 271

2 McNeil, M., Darvill, A.G. and Albersheim, P. Plant Physiol. 1980, 66, 1128

3 Colquhoun, I.J., de Ruiter, G.A., Schols, H.A. and Voragen, A.G.J. Carbohydr. Res. 1990, 206, 131

4 Thibault, J.-F. Phytochemistry 1983, 22, 1567

5 Schols, H.A., Geraeds, C.C.J.M., Searle-van Leeuwen, M.J.F. Kormelink, F.J.M. and Voragen, A.G.J. Carbohydr. Res. 1990, 206, 105

6 Sakamoto, T. and Sakai, T. Carbohydr. Res. 1994, 259, 77

7 Renard, C.M.G.C., Thibault, J.-F., Voragen, A.G.J. van den Broek, L.A.M. and Pilnik, W. Carbohydr. Polym. 1993, 22, 203

8 Renard, C.M.G.C., Crépeau, M.-J. and Thibault, J.-F. Ind. Crops Products 1994, 3, 75

9 Thibault, J.-F. J. Chromatogr. 1980, 194, 315

10 Thibault, J.-F. Lebensmittel Wissenschaft Technol. 1979, 12, 247

11 Tollier, M.-T. and Robin, J.P. Ann. Technol. Agric. 1979, 28, 1

12 Englyst, H.N. and Cummings, J.H. Analyst 1984, 109, 937

13 Quemener, B. and Thibault, J.-F. Carbohydr. Res. 1990, 206, 277

14 Voragen, A.G.J., Schols, H.A. and Pilnik, W. Food H ydrocoll. 1986, 1, 65

15 Schols, H.A., Voragen, A.G.J. and Colquhoun, I.J. Carbohydr. Res. 1994, 256, 97

16 Johansson, I., Lindberg, B. and Theander, O. Acta Chem. Scand. $1963,17,2019$

17 Mutter, M., Beldman, G., Schols, H.A. and Voragen, A.G.J. Plant Physiol. 1994, 106, 241 